\title{
Helicobacter pylori Induces RANTES through Activation of NF-кB
}

\author{
Naoki Mori, ${ }^{1 *}$ Alan M. Krensky, ${ }^{2}$ Romas Geleziunas, ${ }^{3}$ Akihiro Wada, ${ }^{4}$ Toshiya Hirayama, ${ }^{4}$ \\ Chihiro Sasakawa, ${ }^{5}$ and Naoki Yamamoto ${ }^{6}$ \\ Department of Virology, Faculty of Medicine, University of the Ryukyus, Okinawa, ${ }^{1}$ Department of Bacteriology, Institute of \\ Tropical Medicine, Nagasaki University, Nagasaki, ${ }^{4}$ and Department of Microbiology and Immunology, Institute of \\ Medical Science, University of Tokyo, ${ }^{5}$ and Department of Molecular Virology, Graduate School of Medicine, \\ Tokyo Medical and Dental University, ${ }^{6}$ Tokyo, Japan; Department of Pediatrics, Stanford \\ University School of Medicine, Stanford, California ${ }^{2}$; and Merck Research Laboratories, \\ Merck \& Company, Inc., West Point, Pennsylvania ${ }^{3}$
}

Received 26 November 2002/Returned for modification 23 January 2003/Accepted 31 March 2003

\begin{abstract}
Helicobacter pylori-infected gastric mucosa displays a conspicuous infiltration of mononuclear cells and neutrophils. RANTES (short for "regulated upon activation, normal T cell expressed and secreted") is a chemoattractant cytokine (chemokine) important in the infiltration of T lymphocytes and monocytes. RANTES may therefore contribute to the cellular infiltrate in the $\mathrm{H}$. pylori-infected gastric mucosa. The aim of this study was to analyze the molecular mechanism responsible for $H$. pylori-mediated RANTES expression. We observed that gastric epithelial cells produced RANTES upon coculture with $\boldsymbol{H}$. pylori. In addition, $\boldsymbol{H}$. pylori induced RANTES mRNA expression and an increase in luciferase activity in cells which were transfected with a luciferase reporter construct derived from the RANTES promoter, in gastric epithelial cells, indicating that the induction of RANTES production occurred at the transcriptional level. Induction of RANTES was dependent on an intact cag pathogenicity island. Activation of the RANTES promoter by $H$. pylori occurred through the

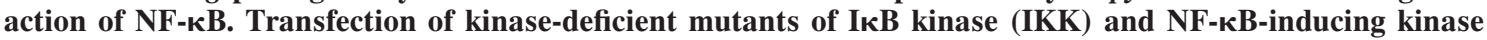
(NIK) inhibited $\boldsymbol{H}$. pylori-mediated RANTES activation. In contrast, tumor necrosis factor alpha- or interleukin-1/Toll-like receptor signaling molecules-such as mitogen-activated protein kinase/extracellular signalregulated kinase kinase $1, \mathrm{MyD88}$, and interleukin-1 receptor-associated kinase- did not play a role in RANTES activation by $H$. pylori. Collectively, $H$. pylori induced NF- $\mathrm{B}$ activation through an intracellular signaling pathway that involved IKK and NIK, leading to RANTES gene transcription. RANTES induction by $H$. pylori may play an important role in gastric inflammation.
\end{abstract}

The microaerophilic bacterium Helicobacter pylori plays an important role in the pathogenesis of chronic gastritis, peptic ulcer, gastric adenocarcinoma, and gastric mucosa-associated lymphoid tissue lymphoma $(14,17,32,33,36)$. H. pylori-infected gastric mucosa from patients with active chronic inflammation is characterized by infiltration of various inflammatory cells, including polymorphonuclear leukocytes, lymphocytes, and cells of a macrophage lineage (13). The epithelial cytokine/ chemokine response is particularly important in the early stages of $H$. pylori-induced inflammation. The functions of chemokines include attracting blood leukocytes to sites of inflammation $(4,41)$, regulating leukocyte maturation, trafficking and homing, and the development of lymphoid tissues $(3,29)$. Although most infected individuals develop only superficial gastritis, some patients progress to chronic gastritis, duodenal ulceration, or, rarely, cancer. This variability in clinical manifestation may arise because of differences in virulence of individual $H$. pylori strains. Several virulence factors have been described and include the presence of a vacuolating cytotoxin, $v a c A$, and a cytotoxin-associated antigen $\mathrm{A}, \operatorname{cag} A(9,38)$. Individuals infected with $c a g A$-positive $H$. pylori strains display more severe gastric inflammation and gastroduodenal ulcer disease and appear to develop gastric adenocarcinomas more

\footnotetext{
* Corresponding author. Mailing address: Department of Virology, Faculty of Medicine, University of the Ryukyus, 207 Uehara, Nishihara, Okinawa 903-0215, Japan. Phone: 81-98-895-1130. Fax: 81-98895-1410. E-mail: n-mori@med.u-ryukyu.ac.jp.
}

frequently $(5,10)$. Both in vitro and in vivo, $\operatorname{cag} A$-positive strains elicit a significantly higher interleukin-8 (IL-8) response than $\operatorname{cag} A$-lacking strains $(11,37)$. However, numerous studies have indicated that not $c a g A$ itself, but products of other genes in the cag pathogenicity island (cag PAI), about a 40-kb region of possibly extraneous origin, are responsible for IL-8 induction $(7,21,47)$.

Although many studies have supported the causative role of IL-8 for the prominent neutrophil accumulation in $H$. pyloriinfected gastric mucosa, which results in multifocal mucosal damage and atrophy, little is known about the mediators responsible for the infiltration of inflammatory cells other than polymorphonuclear leukocytes in this disease. RANTES (short for "regulated upon activation, normal $\mathrm{T}$ cell expressed and secreted") is a member of the large and growing family of immunoregulatory cytokines called chemokines. RANTES belongs to the C-C chemokine subfamily. It is a potent chemotactic agent for $\mathrm{T}$ lymphocytes and monocytes (40) and is expressed after cellular activation in fibroblasts, T cells, monocytes, endothelial cells, and certain epithelial cells. RANTES may therefore contribute to the infiltration of lymphocytes in the $H$. pylori-infected gastric mucosa. Like that of IL-8, RANTES expression is increased in vitro and in vivo in gastric mucosa following $H$. pylori infection $(8,42,50)$. Persistent expression and secretion of RANTES are closely related to residual infiltration of memory $\mathrm{T}$ lymphocytes for a prolonged period after $H$. pylori eradication (19).

The present study was designed to evaluate the effect of $H$. 
pylori on the expression of RANTES in gastric epithelial cells in vitro and to study the role of $H$. pylori virulence factors in any such effect. We found that $H$. pylori induces RANTES production and activates RANTES gene expression in gastric epithelial cells. We also showed that two NF-кB elements are essential for $H$. pylori-induced activation of RANTES gene expression. This was related to the expression of cag PAI responsible for cytokine/chemokine production. Finally, we observed that RANTES gene activation was inhibited by transfection of a kinase-deficient mutant of NF-кB-inducing kinase (NIK) or IкB kinases (IKKs). In conclusion, H. pylori-induced RANTES activation in epithelial cells is dependent on cag PAI and involves NF- $\kappa$ B activation via the NIK-IKK signaling complex.

\section{MATERIALS AND METHODS}

Bacterial strains. H. pylori (ATCC 49503; American Type Culture Collection, Rockville, Md.) was used in most experiments described in this study. Other clinical strains (OHPC0001, OHPC0002, and OHPC0003), isolated from patients with chronic gastritis, were kind gifts from T. Kitahora (Ohkura Hospital, Tokyo, Japan). An isogenic H. pylori mutant lacking the cag PAI was also studied together with its parental wild-type strain (26695). The presence of cag PAI and $v a c A$ in these strains was determined by PCR using specific sets of primers (Fig. $1 \mathrm{~A}$ and data not shown) $(1,48)$. H. pylori strains were recovered from frozen stocks by seeding them on a blood agar plate (Mueller-Hinton II agar with 7\% horse blood) at $37^{\circ} \mathrm{C}$ for 3 days under microaerophilic conditions $\left(10 \% \mathrm{O}_{2}-10 \%\right.$ $\mathrm{CO}_{2}$ ) generated with Anaeropack Campylo (Mitsubishi Gas Chemicals Co., Tokyo, Japan). Bacteria harvested from the plates, using cotton swabs, were suspended in $200 \mathrm{ml}$ of brain heart infusion broth containing $10 \%$ fetal calf serum and were then liquid cultured at $37^{\circ} \mathrm{C}$ for 2 days with vigorous shaking in a controlled microaerophilic environment. Bacteria were harvested from the broth culture by centrifugation and were resuspended at the indicated concentrations in antibiotic-free medium. Cultured bacteria reached a density of $4 \times$ $10^{8} \mathrm{CFU} / \mathrm{ml}$. All procedures were performed with the approval of the appropriate institutional biosafety review committees and in compliance with their guidelines for biohazards.

Cell culture. Human gastric epithelial cells, MKN45, were maintained in RPMI 1640 medium containing 10\% fetal bovine serum (HyClone Laboratories, Inc., Logan, Utah), penicillin $\mathrm{G}(100 \mathrm{U} / \mathrm{ml})$, and streptomycin $(100 \mu \mathrm{g} / \mathrm{ml})$. This cell line was established from a poorly differentiated adenocarcinoma metastasized to liver and obtained from the Health Science Research Resources Bank (Osaka, Japan). On the day of the experiment, cells were refed with fresh serumand antibiotic-free medium and cocultured with $H$. pylori to a final concentration of $10^{7} \mathrm{CFU} / \mathrm{ml}$ for the indicated time intervals.

RANTES measurement. The RANTES content in the culture supernatants was measured by enzyme-linked immunosorbent assay (BioSource International, Inc., Camarillo, Calif.). MKN45 cells were cultured in RPMI 1640 supplemented with $10 \%$ fetal bovine serum in 24-well plates. Subconfluent monolayers of MKN45 cells were cocultured with $H$. pylori for $24 \mathrm{~h}$. The supernatants were then collected after centrifugation to remove bacteria and stored at $-80^{\circ} \mathrm{C}$ until assayed for RANTES by enzyme-linked immunosorbent assay. The concentration of RANTES was determined using a standard curve obtained with recombinant RANTES.

Reverse transcription (RT)-PCR. Total cellular RNA was extracted with Trizol (Life Technologies, Gaithersburg, Md.) according to the protocol provided by the manufacturer, and the amount of total RNA was determined by measuring the absorbance at $260 \mathrm{~nm}$. First-strand cDNA was synthesized from 1 $\mu \mathrm{g}$ of total cellular RNA in a $20-\mu \mathrm{l}$ reaction volume using an RNA PCR kit (Takara Shuzo, Kyoto, Japan) with random primers. Thereafter, cDNA was amplified for 30 and 28 cycles for RANTES and $\beta$-actin, respectively. The oligonucleotide primers used were as follows: for RANTES, sense, $5^{\prime}$-CCGTG CCCACATCAAGGAGTATTT-3', and antisense, 5'-CCAGCCTGGGGAAG GTTTTTGTAA-3' (2); and for $\beta$-actin, sense, $5^{\prime}$-GTGGGGCGCCCCAGGCA CCA-3', and antisense, 5'-CTCCTTAATGTCACGCACGATTTC-3'. Product sizes were $311 \mathrm{bp}$ for RANTES and $548 \mathrm{bp}$ for $\beta$-actin. Cycling conditions were as follows: denaturing at $94^{\circ} \mathrm{C}$ for $45 \mathrm{~s}$ (for RANTES) or for $30 \mathrm{~s}$ (for $\beta$-actin), annealing at $57^{\circ} \mathrm{C}$ for $90 \mathrm{~s}$ (for RANTES) or $60^{\circ} \mathrm{C}$ for $30 \mathrm{~s}$ (for $\beta$-actin), and extension at $72^{\circ} \mathrm{C}$ for $90 \mathrm{~s}$. The PCR products were fractionated on $2 \%$ agarose gels and visualized by ethidium bromide staining.
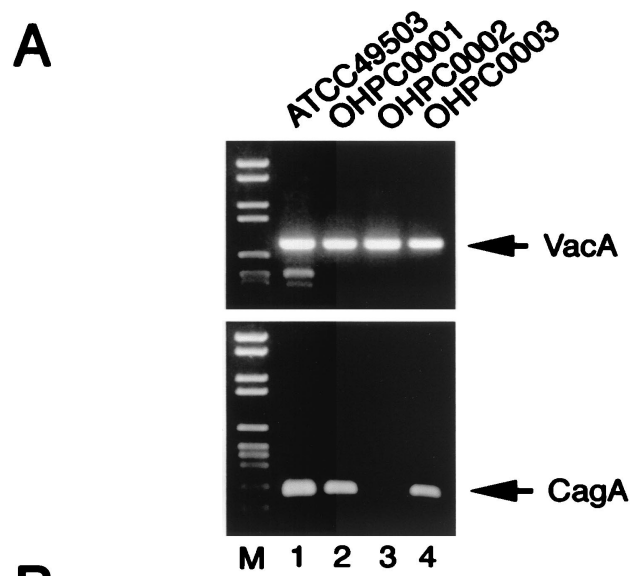

B

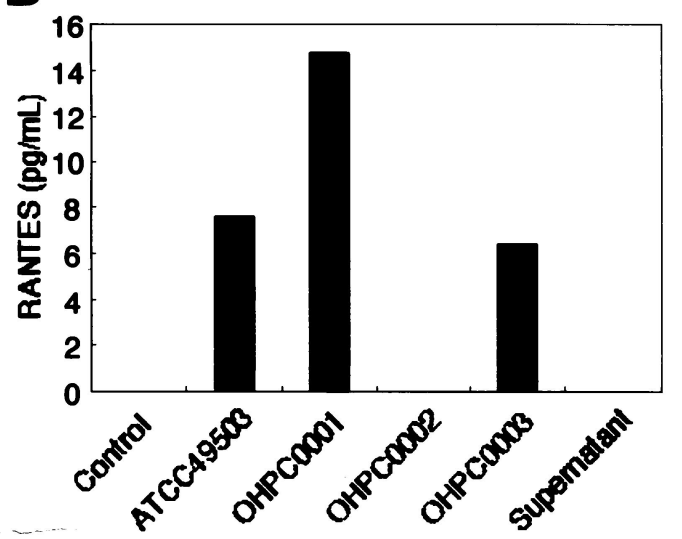

FIG. 1. RANTES production in MKN45 cells by clinical isolates and type strain of $H$. pylori. (A) Genotype of clinical isolates and type strain of $H$. pylori. The presence of $c a g A$ and $v a c A$ in these strains was determined by PCR. (B) cag PAI-positive H. pylori strains increase RANTES production. MKN45 cells were incubated with $H$. pylori $(50$ organisms/cell) for $24 \mathrm{~h}$. RANTES contents in supernatants were determined as described in Materials and Methods.

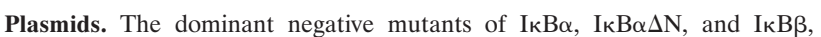
I $\kappa \beta \beta \Delta$ N (kindly provided by D. W. Ballard, Vanderbilt University School of Medicine, Nashville, Tenn.) are deletion mutants of IкB $\alpha$ and IкB $\beta$ lacking the $\mathrm{NH}_{2}$-terminal 36 amino acids and 23 amino acids, respectively $(6,24)$. The dominant negative mutants of IкB kinase $\alpha(\mathrm{IKK} \alpha)$, IKK $\alpha(\mathrm{K} 44 \mathrm{M})$, and of IKK $\beta, \operatorname{IKK} \beta$ (K44A), and the dominant negative mutant of NIK, NIK (KK429/ 430AA), have been described previously (15). IKK $\alpha$ (K44M) and IKK $\beta$ (K44A) contain methionine and alanine replacements at lysine 44 , respectively. NIK (KK429/430AA) contains alanine replacements at lysines 429 and 430. The dominant negative mutant of mitogen-activated protein kinase/extracellular signal-regulated kinase kinase 1 (MEKK1), MEKK1 (D1369A), was generously donated by M. H. Cobb (University of Texas Southwestern Medical Center, Dallas, Tex.). This plasmid contains an alanine replacement at aspartate 1369 . The dominant negative mutants of IL-1 receptor-associated kinase (IRAK) and MyD88 were generously donated by M. Muzio (Mario Negri Institute, Milan, Italy). The former is a truncated version encoding amino acids 1 to 215 , and the latter is a COOH-terminal region of MyD88 (152 to 296). A series of RANTES promoter pGL2-luciferase reporter constructs described previously $(31,35)$ was used to map $H$. pylori-responsive regions.

Transfection and luciferase assay. MKN45 cells $\left(7 \times 10^{5}\right)$ were transfected with $0.1 \mu \mathrm{g}$ of appropriate reporter and effector plasmids along with $0.6 \mu \mathrm{g}$ of pRL-TK, an internal control Renilla luciferase expression vector (Promega, Madison, Wis.), using Lipofectamine (Life Technologies). After 24 h, H. pylori was added to a final dose of 50 organisms/cell and incubated for $6 \mathrm{~h}$, since higher concentrations of bacteria induced the death of MKN45 cells as determined by a morphological analysis. The cells were washed in phosphate-buffered saline 


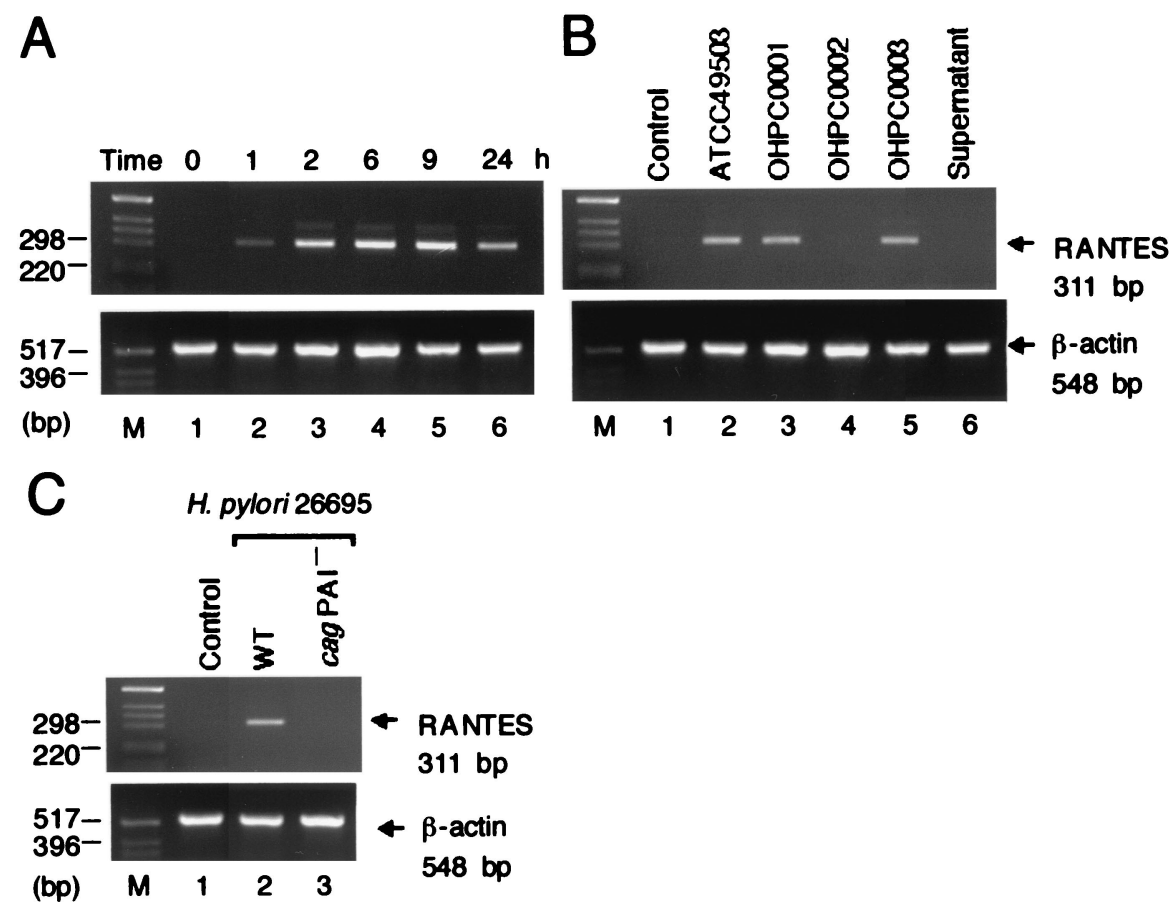

FIG. 2. H. pylori-induced RANTES mRNA expression in MKN45 cells. (A) Time course of $H$. pylori-induced RANTES mRNA expression. Total RNA was extracted from MKN45 cells infected with H. pylori (ATCC 49503) (50 organisms/cell) for the indicated time intervals and used for RT-PCR. (B) cag PAI-positive and cag PAI-lacking $H$. pylori strains differ in their ability to induce RANTES expression. (C) The cag PAI of H. pylori is required for induction of RANTES expression in MNK45 cells. Total RNA was extracted from the cells infected with $H$. pylori for $6 \mathrm{~h}$ and used for RT-PCR. $\beta$-Actin expression served as controls.

and lysed in reporter lysis buffer (Promega). Lysates were assayed for reporter gene activity with the dual luciferase reporter assay system (Promega). In some experiments, MKN45 cells were treated with $20 \mu \mathrm{M}$ Bay 11-7082 (Calbiochem, La Jolla, Calif.), which inhibits NF-кB activation (39). After 1 h of Bay 11-7082 exposure, the cells were then cocultured with $H$. pylori for $6 \mathrm{~h}$.

Nuclear extracts preparation and EMSA. NF- $\kappa$ B binding activity to $\kappa \mathrm{B}$ elements was examined by electrophoretic mobility shift assay (EMSA), as described previously (25). In brief, $5 \mu \mathrm{g}$ of nuclear extracts was preincubated in a binding buffer containing $1 \mu \mathrm{g}$ of poly(dI-dC) (Pharmacia, Piscataway, N.J.), followed by addition of $\alpha-{ }^{32} \mathrm{P}$-labeled oligonucleotide probes containing $\kappa \mathrm{B}$ elements (approximately 50,000 cpm). These mixtures were incubated for $15 \mathrm{~min}$ at room temperature. The DNA protein complexes were separated on a $4 \%$ polyacrylamide gel and visualized by autoradiography. To examine the specificity of the $\mathrm{\kappa B}$ element probes, we preincubated unlabeled competitor oligonucleotides with nuclear extracts for $15 \mathrm{~min}$ before incubation with probes. The probes or competitors used were prepared by annealing the sense and antisense synthetic oligonucleotides as follows: A site NF-кB of the RANTES gene, 5' -tcga ATTTTGGAAACTCCCCTTAGG-3'; B site NF-кB of the RANTES gene, 5' tcgaCTTAGGGGATGCCCCTCAACTG-3'; and a consensus AP-1 binding site, 5'-gatcCGCTTGATGAGTCAGCCGGAA-3'. Underlined sequences represent the NF- $\mathrm{B}$ or AP-1 binding sites, and lowercase letters represent residues added for labeling purposes. To identify NF- $\mathrm{B}$ proteins in the DNA protein complex revealed by EMSA, we used antibodies specific for various NF- $\mathrm{B}$ family proteins, including p65, p50, c-Rel, and p52 (Santa Cruz Biotechnology, Santa Cruz, Calif.), to elicit a supershift DNA protein complex formation. These antibodies were incubated with the nuclear extracts for $45 \mathrm{~min}$ at room temperature before incubation with radiolabeled probes.

\section{RESULTS}

$H$. pylori infection increases RANTES production and steady-state RANTES mRNA levels in gastric epithelial cells. We first examined the capacity of gastric epithelial cells to produce RANTES upon coculture with live H. pylori. A gastric epithelial cell line, MKN45, did not produce RANTES (Fig. 1B). Coculture with live H. pylori (ATCC 49503) induced significantly RANTES production by MKN45 (Fig. 1B). Using RT-PCR, we next examined whether coculture of MKN45 with $H$. pylori leads to the induction of RANTES mRNA. Coculture with H. pylori (ATCC 49503) significantly enhanced steadystate levels of RANTES mRNA in MKN45 cells (Fig. 2A). RANTES transcript levels clearly increased $1 \mathrm{~h}$ after addition of $H$. pylori to the MKN45 cells and remained elevated at least $24 \mathrm{~h}$ following cocultivation (Fig. 2A). Supernatants derived from H. pylori (ATCC 49503) cultures failed to induce RANTES mRNA expression in MKN45 cells (Fig. 2B). Moreover, neither heat-killed bacteria nor live bacteria separated by a permeable membrane induced RANTES mRNA expression in MKN45 cells (data not shown). These results suggest that interaction with live $H$. pylori itself, rather than products secreted by these bacteria, up-regulates the steady-state levels of RANTES mRNA.

H. pylori strains differ in their ability to induce RANTES production and RANTES mRNA expression. Since numerous studies indicated that expression of multiple genes in the cag PAI is necessary for cytokine production by gastric epithelial cells in vitro $(7,21,47)$, we examined the ability of several $H$. pylori strains, possessing or lacking the cag PAI, to induce RANTES production and RANTES mRNA expression. Infection with $H$. pylori strains ATCC 49503, OHPC0001, and OHPC0003 led to increased RANTES production (Fig. 1B) and RANTES mRNA levels (Fig. 2B) in MKN45 cells. Strain OHPC0002 failed to induce RANTES production (Fig. 1B) 
and RANTES mRNA levels (Fig. 2B). OHPC0002 lacks the cagA gene in cag PAI (Fig. 1A). Previously, we amplified six fragments by long-distance PCR for linkage throughout cag PAI, and confirmed that ATCC 49503, OHPC0001, and OHPC0003 had the entire cag PAI, whereas OHPC0002 totally lacked the cag PAI (48). To determine whether the observed difference in RANTES mRNA expression was specific to the cag PAI, we next examined a wild-type cag PAI-positive $H$. pylori strain (26695) and an isogenic cag PAI mutant. As expected, stimulation with the wild-type strain 26695 induced RANTES mRNA expression in MKN45 cells (Fig. 2C). The isogenic mutant that lacked expression of cag PAI did not induce RANTES mRNA expression (Fig. 2C). The ability of $H$. pylori to induce RANTES production and RANTES mRNA expression was independent of the vacA locus, as all bacterial isolates possessed this gene (Fig. 1A). Furthermore, strain OHPC0001 induced RANTES production and RANTES mRNA expression despite the absence of vacuolating cytotoxin (data not shown). These results suggest that the H. pylori cag PAI plays an important role in the induction of RANTES production and RANTES mRNA expression.

$H$. pylori regulates RANTES gene transcription. Actually, RANTES expression is regulated both translationally and transcriptionally $(43,45)$. In the next series of experiments, we investigated whether $H$. pylori-mediated up-regulation of RANTES gene expression could directly enhance the activity of its promoter. MKN45 cells were transiently transfected with a reporter gene construct containing the -195 nucleotides of the RANTES upstream regulatory sequences. The activity of this RANTES-driven reporter construct was significantly increased after the addition of $H$. pylori (ATCC 49503) when the ratio of bacteria to epithelial cells was 5:1 (Fig. 3B). The highest RANTES promoter activity was observed after infection when the ratio of bacteria to cells was 50:1. No further increase in RANTES promoter activity was evident with a higher infecting dose of bacteria (500 organisms/cell), which induced the death of MKN45 cells. The RANTES promoter has been subdivided into five regions (A through E) based upon deletion studies and reporter gene assays (Fig. 3A) (30, $31,35)$. The A site is very important for the promoter activity since point mutations decrease the activity by $90 \%(27,30)$. The A site contains NF-кB-like characteristics (GGAAACTC $\mathrm{CC}$ ), especially when analyzed on the opposite DNA strand (GGGAGTTTCC), and binds both NF- $\mathrm{KB}$ family proteins and RANTES factor of late-activated T lymphocytes-1 (also named Kruppel-like factor [43]) $(30,44)$. The B site also contains a consensus for a nearly palindromic NF-кB-like binding site (GGGGATGCCCC) (30). The $\mathrm{C}$ site and $\mathrm{E}$ site bind nuclear proteins that are strongly induced between days 3 and 5 after activation of normal peripheral blood T cells (35). To test the relative contributions of these five regions to $H$. pylori-mediated activation of RANTES, plasmids with deletions in these regions of the RANTES promoter were transfected (Fig. 3C). Coculture of $H$. pylori caused a 4.6-fold rise in the activity of the pGL2-R-luciferase construct. Deletion of either the A site, the B site, or both sites abolished $H$. pylori-mediated activation of this reporter construct. When the $\mathrm{C}$ or $\mathrm{E}$ site was deleted, $H$. pylori-mediated induction was not significantly impaired, indicating that these sites mainly do not affect $H$. pylori mediated RANTES induction in epithelial cells. Thus, only the A and B sites, but not the $\mathrm{E}$ and $\mathrm{C}$ sites, represented major $H$. pyloriresponsive elements within the RANTES transcriptional regulatory sequences. This was confirmed with a reporter gene construct containing only three A and B sites. H. pylori infection significantly induced RANTES gene expression when the pGL2-SV40-(AB)3-luciferase construct was used for the transfection.

$H$. pylori infection of gastric epithelial cells induces binding

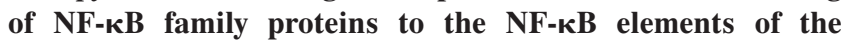
RANTES promoter. Because the deletional analyses of the RANTES promoter indicated that $H$. pylori infection activated transcription through the $\mathrm{A}$ and $\mathrm{B}$ sites, it was important to identify the nuclear factors that bind to these sites. The NF$\kappa \mathrm{B}$-like regions within $\mathrm{A}$ and $\mathrm{B}$ sites derived from the RANTES promoter were used as probes in the EMSA. MKN45 cells were infected with $H$. pylori (ATCC 49503), and at different time points after challenge, nuclear protein extracts were prepared and analyzed for NF- $\mathrm{B}$ DNA binding activity. As shown in Fig. 4A, a complex formed with the A and B oligonucleotide probes was induced in MKN45 cells within 60 min after infection with $H$. pylori. This complex was specific to the A or B fragment because it was reduced by the addition of excess A or B oligonucleotide (Fig. 4C, lanes 2 and 9), but not by an unrelated oligonucleotide containing a consensus AP-1 sequence (Fig. 4C, lanes 3 and 10). Next, we characterized the H. pylori-induced complexes identified by the RANTES A and $\mathrm{B}$ probes. These complexes most likely contain members of the

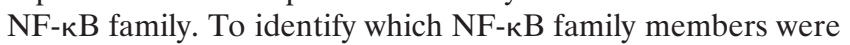
binding to the A and B sites in the RANTES promoter, we performed the EMSA using antibodies specific for members of the NF-кB family. Preincubation with anti-c-Rel or anti-p52 antibody did not affect these complexes (Fig. 4C, lanes 6, 7, 13, and 14), but these complexes were supershifted by the addition of anti-p50 or anti-p65 antibody (Fig. 4C, lanes 4, 5, 11, and 12). These results suggest that $H$. pylori-induced RANTES NF- $\mathrm{kB}$ binding activity is composed of $\mathrm{p} 50$ and $\mathrm{p} 65$. Therefore, H. pylori infection induces RANTES gene expression, at least in part through the induced binding of p50 and p 65 to NF-кB sites within either the A or B site in the RANTES promoter region.

Since we have shown that the cag PAI-positive strains induce significantly more RANTES mRNA than do cag PAI-lacking H. pylori strains, we sought to determine whether cag PAIpositive H. pylori strains better induced NF-кB (Fig. 4B). Markedly increased NF-кB DNA binding activity on A and B probes was induced by cag PAI-positive $H$. pylori strains (lanes 2, 3, 5, 7, 8, and 10) compared with the cag PAI-lacking strain (lanes 4 and 9). These results indicate that the increased ability of cag PAI-positive strains to activate NF-kB binding may play a key role in the observed activation of the RANTES promoter by these bacterial strains. Thus, $H$. pylori infection induces RANTES gene expression, at least in part, through the induced binding of $\mathrm{p} 50$ and $\mathrm{p} 65 \mathrm{NF}-\mathrm{\kappa} B$ family members to the $\kappa \mathrm{B}$ elements within $\mathrm{A}$ and $\mathrm{B}$ sites of the RANTES promoter, and this effect is dependent on cag PAI products.

$H$. pylori-induced activation of the RANTES promoter can be blocked by Bay 11-7082 or dominant interfering signaling components of the NF-kB pathway. We next examined whether H. pylori-mediated activation of RANTES gene expression involves signal transduction components in NF- $\mathrm{KB}$ 

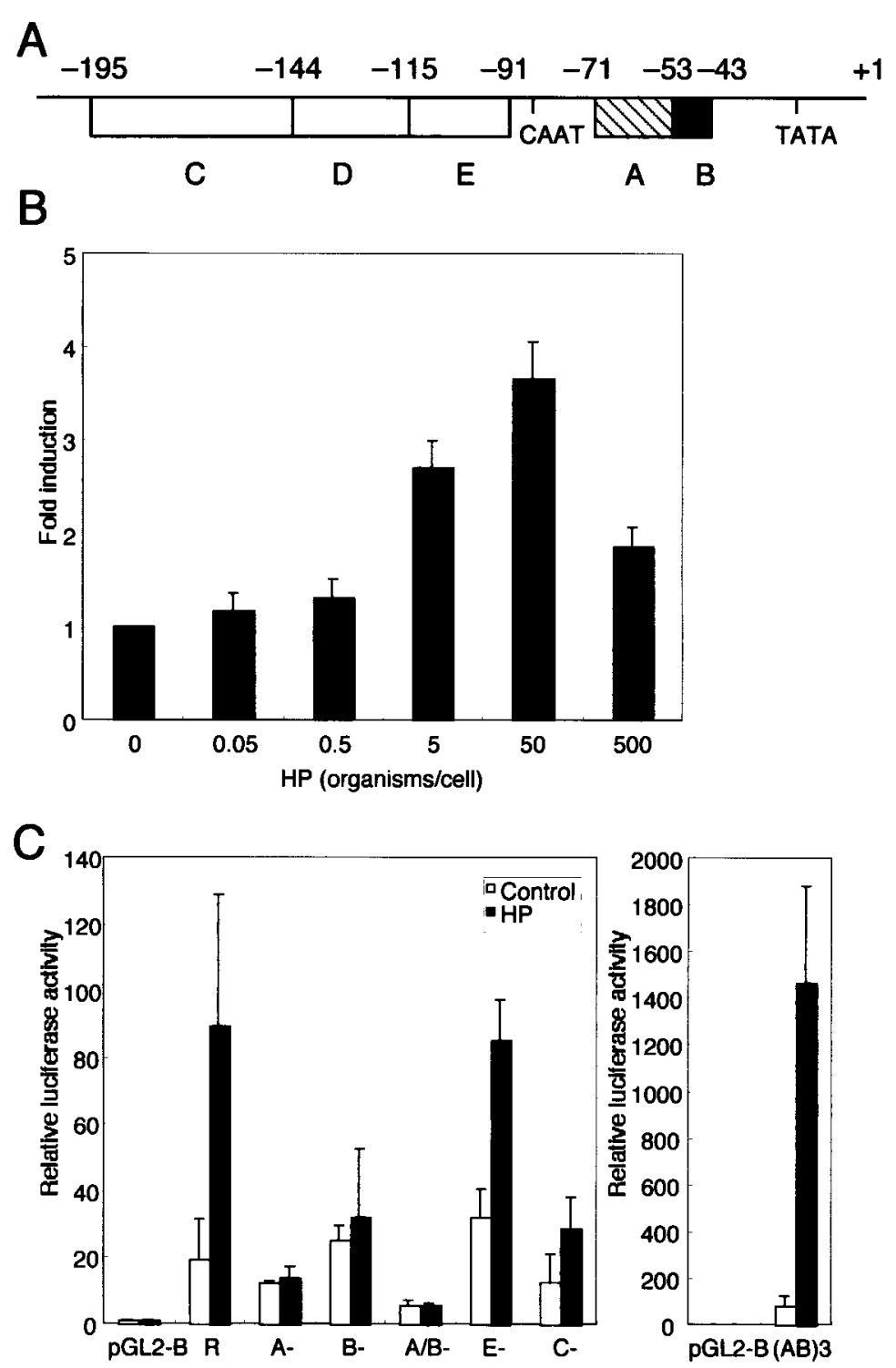

FIG. 3. H. pylori infection activates the RANTES promoter in gastric epithelial cells. (A) Diagram of regulatory regions in the -195 RANTES promoter and their positions relative to the transcription start site at +1 . (B) $H$. pylori infection increases RANTES promoter activity in a dose-dependent fashion. pGL2-R-luciferase construct $(0.1 \mu \mathrm{g})$ containing the complete 195-bp RANTES promoter region immediately upstream of the transcription start site was transfected into MKN45 cells, and the cells were subsequently infected with various concentrations of $H$. pylori (ATCC 49503 ) for $6 \mathrm{~h}$ before the luciferase assay. Luciferase activity is presented as induction relative to the basal level measured in uninfected cells. (C) Mutational analysis of the cis elements required for $H$. pylori-induced RANTES promoter activity. Luciferase reporter constructs $(0.1 \mu \mathrm{g})$ derived from the RANTES promoter were transfected into MKN45 cells, and the cells were subsequently infected with $H$. pylori (ATCC 49503) (50 organisms/cells) for $6 \mathrm{~h}$. The activities are expressed relative to that of cells transfected with pGL2-Basic without further treatment, which was defined as 1. Data are means \pm standard deviations of three independent experiments. Abbreviations: R, pGL2-R-luciferase construct; A-, B-, $\mathrm{A} / \mathrm{B}-, \mathrm{E}-$, and $\mathrm{C}-$, reporter gene constructs derived from pGL2-R-luciferase with the A, B, A and B, E, and C sites, respectively, deleted; (AB)3, pGL2-SV40-(AB)3-luciferase.

activation. The activation of $\mathrm{NF}-\kappa \mathrm{B}$ requires phosphorylation of two conserved serine residues of I $\mathrm{KB} \alpha$ (Ser-32 and Ser-36) and IкB $\beta$ (Ser-19 and Ser-23) within their $\mathrm{NH}_{2}$-terminal domain (16). Phosphorylation leads to ubiquitination and the $26 \mathrm{~S}$ proteasome-mediated degradation of ІкBs, thereby releasing NF- $\kappa \mathrm{B}$ from the complex to translocate to the nucleus and activate genes (16). Bay 11-7082 potently inhibits NF-кB activation through the inhibition of IкB $\alpha$ phosphorylation, thereby preventing NF-кB-mediated transcriptional activation $(26,39)$.
Bay 11-7082 induces apoptosis in cells with constitutive activity of the NF-кB pathway, but not in normal peripheral blood mononuclear cells (26). We used Bay 11-7082 to show a link between NF-кB activation and up-regulation of RANTES promoter activity in $H$. pylori-infected MKN45 cells. We transfected a pGL2-R-luciferase construct and observed the influence of Bay 11-7082. Bay 11-7082 significantly inhibited RANTES transcription (Fig. 5A). We examined the cytotoxic effects of Bay 11-7082 on MKN45 cells by means of the trypan 


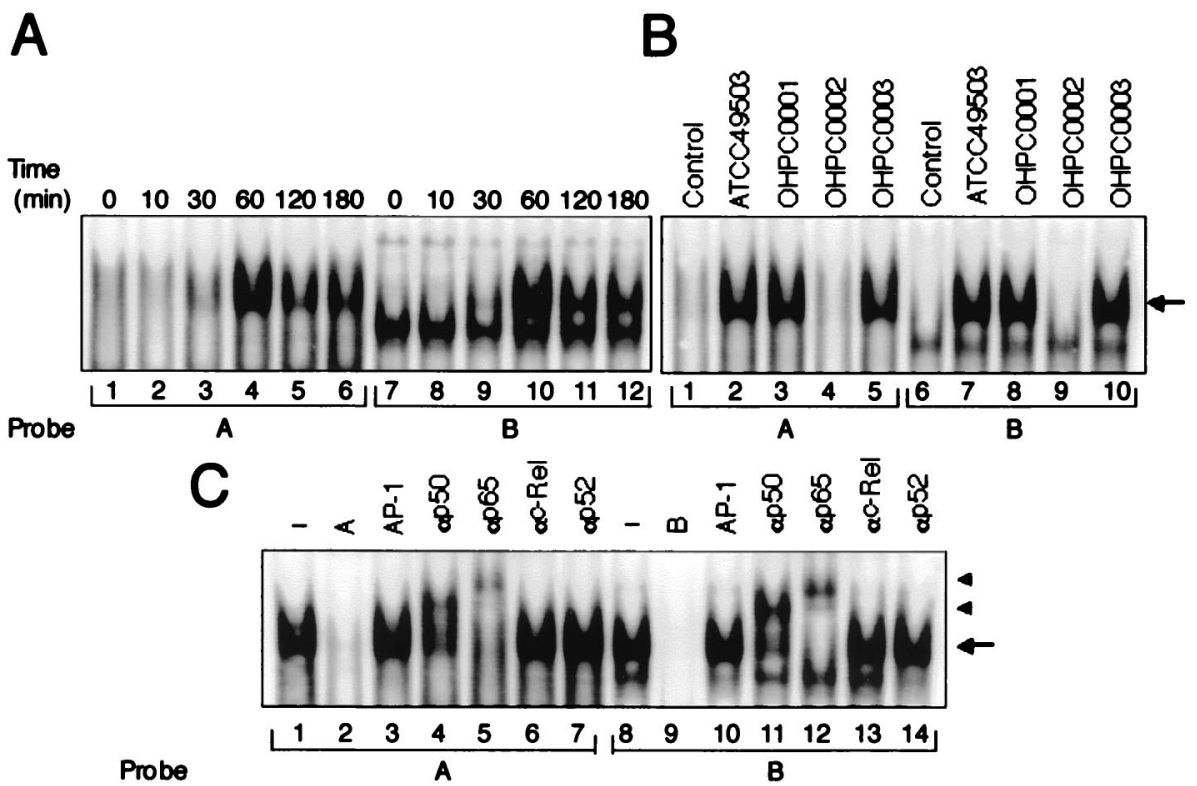

FIG. 4. H. pylori infection-induced NF-кB binding activity. (A) Time course of NF-кB activation in MKN45 cells infected with $H$. pylori, evaluated by EMSA. Nuclear extracts from MKN45 cells, infected with H. pylori (ATCC 49503) (50 organisms/cell) for the indicated time periods, were mixed with either A or B ${ }^{32} \mathrm{P}$-labeled probes. Probes A and B are fragments spanning bp -59 to -39 and bp -44 to -23 , containing NF-кB binding sites of the RANTES promoter, respectively. (B) cag PAI products of $H$. pylori are required for induction of NF- $\mathrm{kB}$ binding activity in MKN45 cells. Nuclear extracts from uninfected MKN45 cells (lanes 1 and 6) and cells cocultured with the indicated $H$. pylori strains (50 organisms/cell) for $60 \mathrm{~min}$ (lanes 2 to 5 and 7 to 10) were analyzed for NF-кB. (C) Sequence specificity of NF-кB binding activity and characterization of NF-кB proteins that bound to the NF-кB binding sites within A and B sites of the RANTES gene. Competition assays were performed with nuclear extracts from MKN45 cells infected with H. pylori (ATCC 49503) (50 organisms/cell) for 60 min. Competitors used were the A (lane 2) and B (lane 9) sites for NF-кB of the RANTES gene. An unrelated AP-1 binding site was also used as a competitor (lanes 3 and 10). Where indicated, 100-fold excess amounts of each specific competitor oligonucleotide (lanes 2, 3, 9, and 10) were added to the reaction mixture with labeled probe A (lanes 1 to 7) or B (lanes 8 to 14). Specific bands are indicated by arrows. Supershift assay of NF-кB DNA-binding complexes in the same nuclear extracts was also performed. Gel shift assay reaction mixtures containing the same nuclear extracts and indicated antibodies were incubated for $45 \mathrm{~min}$, and then ${ }^{32} \mathrm{P}$-labeled probes were added (lanes 4 to 7 and 11 to 14 ). Supershifted bands with anti-NF- $\mathrm{B}$ p50 and anti-NF-кB p65 antibodies are indicated by arrowheads (lanes 4, 5, 11, and 12).

blue dye exclusion test. Importantly, Bay 11-7082 did not affect the survival of MKN45 cells (data not shown).

A high-molecular-weight complex, IKK complex, which is composed of two catalytic subunits, IKK $\alpha$ and IKK $\beta$, and a regulatory subunit, IKK $\gamma$, phosphorylates IкBs (18). Recent studies indicated that members of the mitogen-activated protein kinase kinase kinase protein kinase family mediate physiologic activation of IKK (51). These kinases include NIK (49) and MEKK1 (20). Dominant interfering mutants of $\mathrm{I} \kappa \mathrm{B} \alpha$ and I $\mathrm{B} \beta$ and kinase-deficient mutants of IKK $\alpha$, IKK $\beta$, NIK, and MEKK1 were tested for their ability to inhibit $H$. pylori-mediated activation of the RANTES-driven reporter gene. Expression of these various inhibitory mutants except for the dominant negative mutant of MEKK1, abolished the induction of the RANTES promoter by $H$. pylori infection (Fig. 5B). The signaling pathways leading from tumor necrosis factor (TNF)$\alpha$ and IL-1 receptor activation to NF- $\mathrm{KB}$ have been best characterized. The recently described human Toll-like receptors (TLRs) are members of the IL-1 receptor family of proteins, and signaling from these receptors appears to be identical with IL-1 signaling (28). Although the upstream components of activation are distinct, signaling to NF- $\mathrm{BB}$ by TNF- $\alpha$ and Toll/ IL-1 involves activation of NIK and the IKK complex. Like TNF- $\alpha$ and Toll/IL-1 signaling to NF- $\kappa$ B, activation of NF- $\mathrm{B}$ by $H$. pylori requires IKKs and NIK (23). Similar to $H$. pylori,
TNF- $\alpha$ and IL-1 $\beta$ were capable of inducing RANTES expression in MKN45 cells (data not shown). However, the H. pyloriinduced signaling pathway upstream of NIK may be potentially distinct. By using transient transfection to overexpress dominant negative versions of MyD88 and IRAK in MKN45 cells, we examined whether $H$. pylori infection could activate a RANTES-dependent reporter (Fig. 5B). RANTES activation by $H$. pylori did not require IL-1/TLR-specific signaling molecules. These data demonstrate that signaling components, NIK and IKK, involved in the activation of NF- $\kappa \mathrm{B}$ are necessary for $H$. pylori activation of the RANTES promoter, but IL-1/TLRspecific signaling molecules, such as MyD88 and IRAK, do not play a role.

\section{DISCUSSION}

Previous studies reported that the expression of RANTES is enhanced in $H$. pylori-infected gastric mucosa at the mRNA level $(42,50)$. The significant correlation between the mucosal RANTES levels and the number of memory $\mathrm{T}$ lymphocytes suggests that RANTES leads to the infiltration and accumulation of memory $\mathrm{T}$ lymphocytes in $H$. pylori-infected gastric mucosa (19). In the present study, we examined the hypothesis that $H$. pylori infection of gastric epithelial cells modulates host cell RANTES expression levels. Coculture with H. pylori sig- 
A
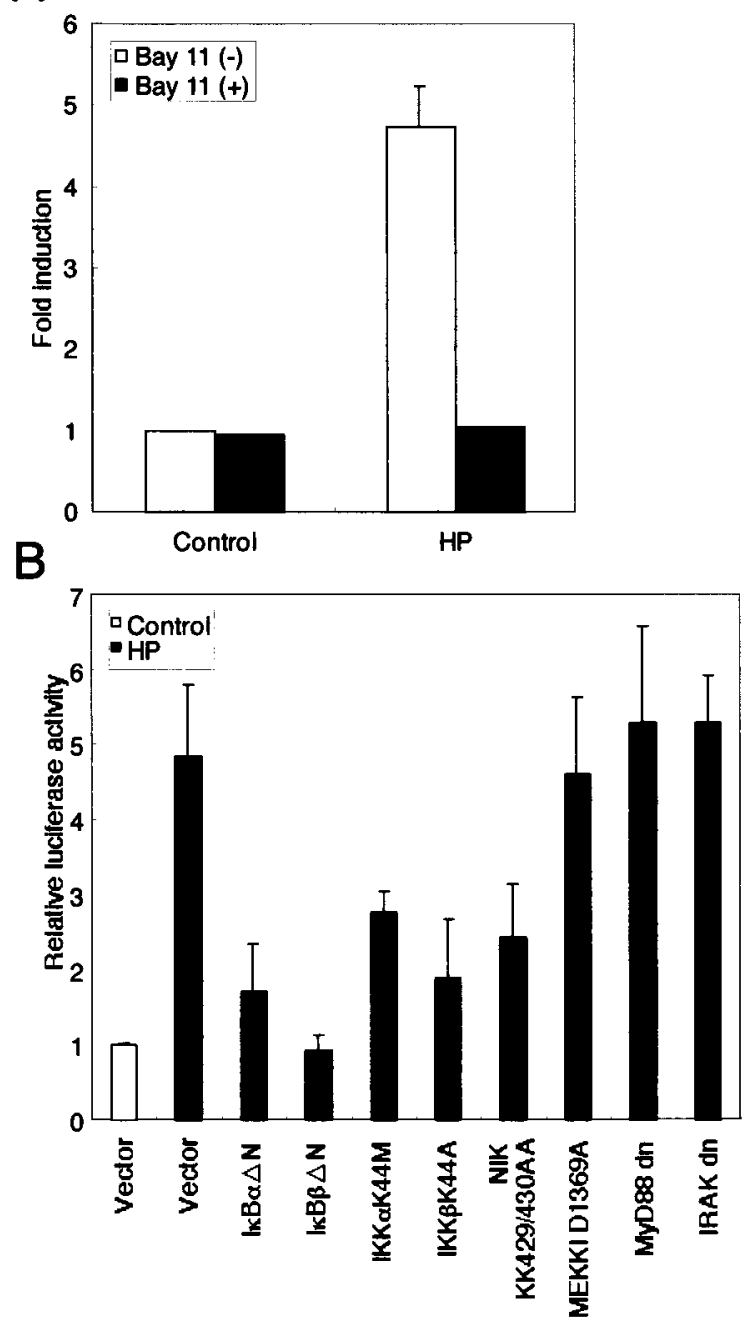

FIG. 5. H. pylori-induced activation of the RANTES promoter can be blocked by Bay 11-7082 or dominant interfering signaling components of the NF-кB pathway. (A) Bay 11-7082 inhibits RANTES activation by $H$. pylori. MKN45 cells were transfected with the pGL2-Rluciferase construct $(0.1 \mu \mathrm{g})$. After $24 \mathrm{~h}$, cells were treated with $20 \mu \mathrm{M}$ Bay 11-7082 for $1 \mathrm{~h}$. Next, cells were cocultured with $H$. pylori (ATCC 49503; 50 organisms/cell) for $6 \mathrm{~h}$. Luciferase activity is presented as induction relative to the basal level measured in uninfected cells. (B) Functional effects of Iк $\mathrm{B} \alpha$ and $\mathrm{I}_{\kappa} \mathrm{B} \beta$ dominant interfering mutants and kinase-deficient IKK $\alpha$, IKK $\beta$, NIK, MEKK1, MyD88, and IRAK mutants on $H$. pylori-induced activation of the RANTES promoter. MKN45 cells were transfected with $0.1 \mu \mathrm{g}$ of pGL2-R-luciferase con-

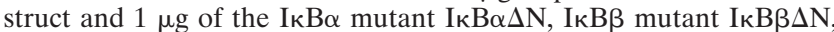
the K44M mutant of IKK $\alpha$, the K44A mutant of IKK $\beta$, the kinasedeficient KK429/430AA mutant of NIK, the dominant negative mutants of MEKK1, MyD88, IRAK, or empty vector (pCMV4) and then infected with $H$. pylori (ATCC 49503) (50 organisms/cell) for $6 \mathrm{~h}$. The open bar represents luciferase activity of the empty vector without $H$. pylori infection. All values were first calculated as induction relative to the basal level measured in uninfected cells. Data are means \pm standard deviations of three independent experiments.

nificantly enhanced steady-state levels of RANTES mRNA in gastric epithelial cells. The enzyme-linked immunosorbent assay data from supernatants of MKN45 cells cocultured with $H$. pylori indicate that MKN45 cells produce comparable levels of
RANTES. In agreement with these findings, Debreceni et al. (12) showed that Helicobacter felis induced RANTES mRNA expression in the normal gastric surface mucous epithelial cell line.

RANTES is expressed relatively late after activation of peripheral blood $\mathrm{T}$ cells by antigen or mitogens but is rapidly induced in normal fibroblasts and epithelial cells by TNF- $\alpha$ and IL-1 $\beta$, suggesting that different control mechanisms may regulate RANTES transcriptional activation (31). Among the multiple regulatory domains identified in the RANTES upstream promoter are two binding sites for the NF-кB transcription factors, located -78 to -42 bp upstream from the transcription initiation site $(27,30)$. Induction of $N F-\kappa B$ plays an important role in RANTES gene activation by stimuli such as phorbol myristate acetate-ionomycin, proinflammatory cytokines, or anti-CD3 and anti-CD28 antibodies (27); furthermore, an NF-AT-like motif and a CD28RE-like motif also serve as NF- $\mathrm{KB}$ binding sites (27). Interferon regulatory factor 3 also plays a role in the regulation of RANTES gene expression (22). The H. pylori-responsive elements within the 5' regulatory sequences of the RANTES gene were localized in A and $\mathrm{B}$ sites. Deletion of the NF- $\mathrm{B}$ sites in this region resulted in loss of $H$. pylori responsiveness, indicating that RANTES regulation by $H$. pylori is mediated by NF- $\mathrm{BB}$ sites. Furthermore, blocking NF-кB activation by Bay 11-7082 markedly inhibited RANTES promoter activity after $H$. pylori infection. These findings suggest that NF- $\mathrm{B}$ activation may be a necessary prerequisite for increased epithelial cell RANTES activation in response to bacterial infection by $H$. pylori. Because neither supernatants of $H$. pylori cultures nor $H$. pylori separated by a permeable membrane induce RANTES expression, components of the $H$. pylori bacterium most likely act to trigger the induction of RANTES in gastric cells. A cag PAI-negative clinical isolate of $H$. pylori is incapable of inducing RANTES expression. Furthermore, we found that the cag PAI-lacking mutant also shows a lack of potency in RANTES induction compared with its cag PAI-positive parental strain. These findings indicate that the gene products of the cag PAI are involved in the induction of RANTES gene expression. Recent studies showed that $H$. pylori type IV secretion system proteins promote migration of CagA protein into gastric epithelial cells, where it is tyrosine phosphorylated and subsequently modulates phosphorylation of host proteins (34). Whether the type IV secretion system of $H$. pylori is also responsible for production of RANTES remains to be determined. In this study, we analyzed the capacities of different $H$. pylori strains to induce RANTES and identified the signaling components NIK and IKKs as likely participants in H. pylori-mediated NF- $\mathrm{BB}$ activation. Compared with the cag PAI-negative $H$. pylori strain, the more virulent cag PAI-positive strains showed an enhanced ability to induce RANTES promoter activity (data not shown) and NF-кB binding activity. This was consistent with our observations that increased RANTES induction in MKN45 cells was associated with cag PAI-positive strains. These results demonstrate that the ability of cag PAI-positive $H$. pylori strains to activate RANTES expression is dependent on prior activation of NF- $\mathrm{B}$ p50 and p65 subunits.

The mammalian signaling pathways triggered by $H$. pylori remain largely unknown. In this study, we identified the cellular kinases NIK and IKKs as participants in NF-кB-dependent 
RANTES induction by $H$. pylori in gastric epithelial cells. In agreement with this, Maeda et al. (23) showed that H. pylori induced NF- $\mathrm{B}$ activation through an intracellular signaling pathway that involves IKKs and NIK. In gram-negative bacteria, lipopolysaccharide is reported to be the most potently inflammatory factor. NF- $\mathrm{kB}$ activation induced by lipopolysaccharide involves CD14/TLR4 through IL-1 receptor signaling molecules, namely, MyD88, IRAK, and TNF receptor-associated factor $6(46,52)$. Because $H$. pylori is a gram-negative bacterium, we investigated whether $H$. pylori-mediated RANTES activation involves CD14/TLR4 in the signaling pathway. TLR4 was expressed in MKN45 cells (data not shown). However, $H$. pylori-induced RANTES activation was not inhibited by dominant negative mutants of MyD88 and IRAK. These findings suggest that a signal transduction molecule in the H. pylori-mediated RANTES activation involves activation of NIK and the IKK complex but does not belong to the IL-1/ TLR superfamily.

In the present study, we showed for the first time the mechanism of $H$. pylori-mediated RANTES activation. NF-кB-mediated RANTES activation is caused through a mechanism independent of IL-1/TLR-specific signaling molecules. We have also shown that pretreatment of cells with Bay 11-7082, which inhibits NF-кB activation, inhibited $H$. pylori-induced RANTES activation. The inflammatory response to $H$. pylori infection is a complicated product of cytokine/chemokine net-

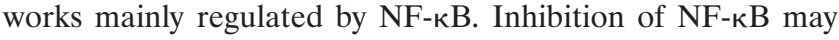
reduce some inflammatory responses caused by $H$. pylori and the associated risk of gastric cancer development.

\section{ACKNOWLEDGMENTS}

We thank T. Kitahora for providing clinical isolates of $H$. pylori; D. W. Ballard for providing the dominant negative mutants of IкB $\alpha$,

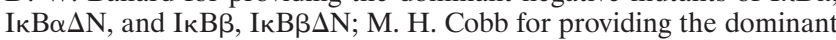
negative mutant of MEKK1, MEKK1 (D1369A); and M. Muzio for providing the dominant negative mutants of MyD88 and IRAK.

\section{REFERENCES}

1. Aihara, M., D. Tsuchimoto, H. Takizawa, A. Azuma, H. Wakebe, Y. Ohmoto, K. Imagawa, M. Kikuchi, N. Mukaida, and K. Matsushima. 1997. Mechanisms involved in Helicobacter pylori-induced interleukin-8 production by a gastric cancer cell line, MKN45. Infect. Immun. 65:3218-3224.

2. Baba, M., T. Imai, T. Yoshida, and O. Yoshie. 1996. Constitutive expression of various chemokine genes in human T-cell lines infected with human T-cell leukemia virus type 1: role of the viral transactivator Tax. Int. J. Cancer 66:124-129.

3. Baggiolini, M. 1998. Chemokines and leukocyte traffic. Nature 392:565-568.

4. Baggiolini, M., B. Dewald, and B. Moser. 1997. Human chemokines: an update. Annu. Rev. Immunol. 15:675-705.

5. Blaser, M. J., G. I. Perez-Perez, H. Kleanthous, T. L. Cover, R. M. Peek, P. H. Chyou, G. N. Stemmermann, and A. Nomura. 1995. Infection with Helicobacter pylori strains possessing cagA is associated with an increased risk of developing adenocarcinoma of the stomach. Cancer Res. 55:2111-2115.

6. Brockman, J. A., D. C. Scherer, T. A. McKinsey, S. M. Hall, X. Qi, W. Y. Lee, and D. W. Ballard. 1995. Coupling of a signal response domain in $\mathrm{I} \kappa \mathrm{B} \alpha$ to multiple pathways for NF-кB activation. Mol. Cell. Biol. 15:2809-2818.

7. Censini, S., C. Lange, Z. Xiang, J. E. Crabtree, P. Ghiara, M. Borodovski, R. Rappuoli, and A. Covacci. 1996. cag, a pathogenicity island of Helicobacter pylori, encodes type I-specific and disease-associated virulence factors. Proc. Natl. Acad. Sci. USA 93:14648-14653.

8. Cottet, S., I. Corthesy-Theulaz, F. Spertini, and B. Corthesy. 2002. Microaerophilic conditions permit to mimic in vitro events occurring during in vivo Helicobacter pylori infection and to identify Rho/Ras-associated proteins in cellular signaling. J. Biol. Chem. 277:33978-33986.

9. Covacci, A., S. Censini, M. Bugnoli, R. Petracca, D. Burroni, G. Macchia, A. Massone, E. Papini, Z. Xiang, N. Figura, and R. Rappuoli. 1993. Molecular characterization of the 128-kDa immunodominant antigen of Helicobacter pylori associated with cytotoxicity and duodenal ulcer. Proc. Natl. Acad. Sci. USA 90:5791-5795.
10. Crabtree, J. E., J. D. Taylor, J. I. Wyatt, R. V. Heatley, T. M. Shallcross, D. S. Tompkins, and B. J. Rathbone. 1991. Mucosal IgA recognition of Helicobacter pylori $120 \mathrm{kDa}$ protein, peptic ulceration, and gastric pathology. Lancet 338:332-335.

11. Crabtree, J. E., S. M. Farmery, I. J. D. Lindley, N. Figura, P. Peichl, and D. S. Tompkins. 1994. CagA/cytotoxin strains of Helicobacter pylori and interleukin-8 in gastric epithelial cell lines. J. Clin. Pathol. 47:945-950.

12. Debreceni, A., K. Okazaki, Y. Matsushima, M. Ohana, H. Nakase, K. Uchida, S. Uose, and T. Chiba. 2001. mRNA expression of cytokines and chemokines in the normal gastric surface mucous epithelial cell line GSM06 during bacterial infection with Helicobacter felis. J. Physiol. 95:461-467.

13. Dixon, M. F. 1995. Histological responses to Helicobacter pylori infection: gastritis, atrophy and preneoplasia. Baillieres Clin. Gastroenterol. 9:467486 .

14. Forman, D., D. G. Newell, F. Fullerton, J. W. Yarnell, A. R. Stacey, N. Wald, and F. Sitas. 1991. Association between infection with Helicobacter pylori and risk of gastric cancer: evidence from a prospective investigation. Br. Med. J. 302:1302-1305.

15. Geleziunas, R., S. Ferrell, X. Lin, Y. Mu, E. T. Cunningham, Jr., M. Grant, M. A. Connelly, J. E. Hambor, K. B. Marcu, and W. C. Greene. 1998. Human T-cell leukemia virus type 1 Tax induction of NF- $\mathrm{B}$ involves activation of the I $\mathrm{B}$ kinase $\alpha(\mathrm{IKK} \alpha)$ and IKK $\beta$ cellular kinases. Mol. Cell. Biol. 18: 5157-5165.

16. Ghosh, S., M. J. May, and E. B. Kopp. 1998. NF-кB and Rel proteins: evolutionarily conserved mediators of immune responses. Annu. Rev. Immunol. 16:225-260.

17. Graham, D. Y., G. M. Lew, P. D. Klein, D. G. Evans, D. J. Evans, Jr., Z. A. Saeed, and H. M. Malaty. 1992. Effect of treatment of Helicobacter pylori infection on the long-terminal recurrence of gastric or duodenal ulcer: a randomized, controlled study. Ann. Intern. Med. 116:705-708.

18. Karin, M., and Y. Ben-Neriah. 2000. Phosphorylation meets ubiquitination: the control of NF-кB activity. Annu. Rev. Immunol. 18:621-663.

19. Kikuchi, T., K. Kato, S. Ohara, H. Sekine, T. Arikawa, T. Suzuki, K. Noguchi, M. Saito, Y. Saito, H. Nagura, T. Toyota, and T. Shimosegawa. 2000. The relationship between persistent secretion of RANTES and residual infiltration of eosinophils and memory $\mathrm{T}$ lymphocytes after Helicobacter pylori eradication. J. Pathol. 192:243-250.

20. Lee, F. S., R. T. Peters, L. C. Dang, and T. Maniatis. 1998. MEKK1 activates both IкB kinase $\alpha$ and IкB kinase $\beta$. Proc. Natl. Acad. Sci. USA 95:93199324.

21. Li, S. D., D. Kersulyte, I. J. D. Lindley, B. Neelam, D. E. Berg, and J. E. Crabtree. 1999. Multiple genes in the left half of the cag pathogenicity island of Helicobacter pylori are required for tyrosine kinase-dependent transcription of interleukin-8 in gastric epithelial cells. Infect. Immun. 67:3893-3899.

22. Lin, R., C. Heylbroeck, P. Genin, P. M. Pitha, and J. Hiscott. 1999. Essential role of interferon regulatory factor 3 in direct activation of RANTES chemokine transcription. Mol. Cell. Biol. 19:959-966.

23. Maeda, S., H. Yoshida, K. Ogura, Y. Mitsuno, Y. Hirata, Y. Yamaji, M. Akanuma, Y. Shiratori, and M. Omata. 2000. H. pylori activates NF-кB through a signaling pathway involving IкB kinases, NF-кB-inducing kinase, TRAF2, and TRAF6 in gastric cancer cells. Gastroenterology 119:97-108.

24. McKinsey, T. A., J. A. Brockman, D. C. Scherer, S. W. Al-Murrani, P. L. Green, and D. W. Ballard. 1996. Inactivation of IкB $\beta$ by the Tax protein of human T-cell leukemia virus type 1: a potential mechanism for constitutive induction of NF-кB. Mol. Cell. Biol. 16:2083-2090.

25. Mori, N., M. Fujii, S. Ikeda, Y. Yamada, M. Tomonaga, D. W. Ballard, and N. Yamamoto. 1999. Constitutive activation of NF-кB in primary adult T-cell leukemia cells. Blood 93:2360-2368.

26. Mori, N., Y. Yamada, S. Ikeda, Y. Yamasaki, K. Tsukasaki, Y. Tanaka, M. Tomonaga, N. Yamamoto, and M. Fujii. 2002. Bay 11-7082 inhibits transcription factor NF-кB and induces apoptosis of HTLV-I-infected T-cell lines and primary adult T-cell leukemia cells. Blood 100:1828-1834.

27. Moriuchi, H., M. Moriuchi, and A. S. Fauci. 1997. Nuclear factor-кB potently up-regulates the promoter activity of RANTES, a chemokine that blocks HIV infection. J. Immunol. 158:3483-3491.

28. Muzio, M., G. Natoli, S. Saccani, M. Lervero, and A. Mantovani. 1998. The human toll signaling pathway: divergence of nuclear factor $\kappa \mathrm{B}$ and JNK/ SAPK activation upstream of tumor necrosis factor receptor-associated factor 6 (TRAF6). J. Exp. Med. 187:2097-2101.

29. Nelson, P. J., and A. M. Krensky. 1998. Chemokines, lymphocytes and viruses: what goes around, comes around. Curr. Opin. Immunol. 10:265-270.

30. Nelson, P. J., B. D. Oritz, J. M. Pattison, and A. M. Krensky. 1996. Identification of a novel regulatory region critical for expression of the RANTES chemokine in activated T lymphocytes. J. Immunol. 157:1139-1148.

31. Nelson, P. J., H. T. Kim, W. C. Manning, T. J. Goralski, and A. M. Krensky. 1993. Genomic organization and transcriptional regulation of the RANTES chemokine gene. J. Immunol. 151:2601-2612.

32. NIH Consensus Development Panel on Helicobacter pylori in Peptic Ulcer Disease. 1994. Helicobacter pylori in peptic ulcer disease. JAMA 272:65-69.

33. Nomura, A., G. N. Stemmermann, P. H. Chyou, I. Kato, G. I. Perez-Perez, and M. J. Blaser. 1991. Helicobacter pylori infection and gastric carcinoma among Japanese Americans in Hawaii. N. Engl. J. Med. 325:1132-1136. 
34. Odenbreit, S., J. Puls, B. Sedlmaier, E. Gerland, W. Fischer, and R. Haas 2000. Translocation of Helicobacter pylori CagA into gastric epithelial cells by type IV secretion. Science 287:1497-1500.

35. Ortiz, B. D., A. M. Krensky, and P. J. Nelson. 1996. Kinetics of transcription factors regulating the RANTES chemokine gene reveal a developmenta switch in nuclear events during T-lymphocyte maturation. Mol. Cell. Biol. 16:202-210.

36. Parsonnet, J., G. D. Friedman, D. P. Vandersteen, Y. Chang, J. H. Vogelman, N. Orentreich, and R. K. Sibley. 1991. Helicobacter pylori infection and the risk of gastric carcinoma. N. Engl. J. Med. 325:1127-1131.

37. Peek, R. M., Jr., G. G. Miller, K. T. Tham, G. I. Perez-Perez, X. Zhao, J. C Atherton, and M. J. Blaser. 1995. Heightened inflammatory response and cytokine expression in vivo to cagA + Helicobacter pylori strains. Lab. Investig. 73:760-770.

38. Phadnis, S. H., D. Ilver, L. Janzon, S. Normark, and T. U. Westblom. 1994 Pathological significance and molecular characterization of the vacuolating toxin gene of Helicobacter pylori. Infect. Immun. 62:1557-1565.

39. Pierce, J. W., R. Schoenleber, G. Jesmok, J. Best, S. A. Moore, T. Collins, and M. E. Gerritsen. 1997. Novel inhibitors of cytokine-induced IкB $\alpha$ phosphorylation and endothelial cell adhesion molecule expression show antiinflammatory effects in vivo. J. Biol. Chem. 272:21096-21103.

40. Schall, T. J., K. Bacon, K. J. Toy, and D. V. Goeddel. 1990. Selective attraction of monocytes and $\mathrm{T}$ lymphocytes of the memory phenotype by cytokine RANTES. Nature 347:669-671.

41. Schluger, N. W., and W. N. Rom. 1997. Early responses to infection: chemokines as mediators of inflammation. Curr. Opin. Immunol. 9:504-508.

42. Shimoyama, T., S. M. Everett, M. F. Dixon, A. T. R. Axon, and J. E. Crabtree. 1998. Chemokine mRNA expression in gastric mucosa is associated with Helicobacter pylori cagA positivity and severity of gastritis. J. Clin. Pathol. 51:765-770.

43. Song, A., T. Nikolcheva, and A. M. Krensky. 2000. Transcriptional regulation of RANTES expression in T lymphocytes. Immunol. Rev. 177:236-245.
44. Song, A., Y.-F. Chen, K. Thamatrakoln, T. A. Storm, and M. Krensky. 1999. RFLAT-1: a new zinc finger transcription factor that activates RANTES gene expression in T lymphocytes. Immunity 10:93-103.

45. Swanson, B. J., M. Murakami, T. C. Mitchell, J. Kappler, and P. Marrack. 2002. RANTES production by memory phenotype T cells is controlled by a posttranscriptional, TCR-dependent process. Immunity 17:605-615.

46. Takeuchi, O., K. Takeda, K. Hoshino, O. Adachi, T. Ogawa, and S. Akira. 2000. Cellular responses to bacterial cell wall components are mediated through MyD88-dependent signaling cascades. Int. Immunol. 12:113-117.

47. Tummuru, M. K. R., S. A. Sharma, and M. J. Blaser. 1995. Helicobacter pylori picB, a homologue of the Bordetella pertussis toxin secretion protein, is required for induction of IL-8 in gastric epithelial cells. Mol. Microbiol. 18:867-876.

48. Wada, A., N. Mori, K. Oishi, H. Hojo, Y. Nakahara, Y. Hamanaka, M. Nagashima, I. Sekine, K. Ogushi, T. Niidome, T. Nagatake, J. Moss, and T. Hirayama. 1999. Induction of human $\beta$-defensin- 2 mRNA expression by Helicobacter pylori in human gastric cell line MKN45 cells on cag pathogenicity island. Biochem. Biophys. Res. Commun. 263:770-774.

49. Woronicz, J. D., X. Gao, Z. Cao, M. Rothe, and D. V. Goeddel. 1997. ІкB kinase- $\beta$ : NF- $\kappa$ B activation and complex formation with IкB kinase- $\alpha$ and NIK. Science 278:866-869.

50. Yamaoka, Y., M. Kita, T. Kodama, N. Sawai, T. Tanahashi, K. Kashima, and J. Imanishi. 1998. Chemokines in the gastric mucosa in Helicobacter pylor infection. Gut 42:609-617.

51. Zandi, E., and M. Karin. 1999. Bridging the gap: composition, regulation, and physiological function of the IкB kinase complex. Mol. Cell. Biol. 19: 4547-4551.

52. Zhang, F. X., C. J. Kirschning, R. Mancinelli, X.-P. Xu, Y. Jin, E. Faure, A. Mantovani, M. Rothe, M. Muzio, and M. Arditi. 1999. Bacterial lipopolysaccharide activates nuclear factor- $\kappa \mathrm{B}$ through interleukin-1 signaling mediators in cultured human dermal endothelial cells and mononuclear phagocytes. J. Biol. Chem. 274:7611-7614.

Editor: J. D. Clements 